\title{
PERCEPÇÕES DOS ESTUDANTES DE LICENCIATURA ACERCA DO CONCEITO DE CURRÍCULO: IMPLICAÇÕES DA CULTURA E CULTURA ESCOLAR NA EDUCAÇÃO
}

\author{
PERCEPCIONES DE LOS ESTUDIANTES DE LICENCIA SOBRE EL CONCEPTO \\ CURRICULAR: IMPLICACIONES DE LA CULTURA Y LA CULTURA ESCOLAR EN \\ LA EDUCACIÓN
}

\section{PERCEPTIONS OF LICENSING STUDENTS ABOUT CURRICULUM CONCEPT: IMPLICATIONS OF CULTURE AND SCHOOL CULTURE IN EDUCATION}

\author{
Andressa Graziele BRANDT ${ }^{1}$ \\ Filomena Lucia Gossler Rodrigues da SILVA ${ }^{2}$ \\ Sonia Regina de Souza FERNANDES ${ }^{3}$ \\ Franc-Lane Sousa Carvalho do NASCIMENTO ${ }^{4}$ \\ Nadja Regina Sousa MAGALHÃES ${ }^{5}$ \\ Joelson de Sousa MORAIS ${ }^{6}$
}

RESUMO: O objetivo deste estudo foi analisar as representações que os estudantes de um Curso de Licenciatura em Pedagogia de um Instituto Federal (IFs) do estado de Santa Catarina possuem em relação a compreensão do conceito de currículo e suas implicações nas políticas curriculares da Educação Básica. Nesta pesquisa de caráter qualitativo, utilizou-se como método a entrevista semiestruturada com perguntas abertas como instrumento de coleta de informações, as quais foram realizadas com 08 estudantes de licenciatura do $7^{\circ}$ e $8^{\circ}$ semestre do referido curso. Os resultados evidenciam que as percepções dos licenciandos estão fundamentadas na compreensão do currículo como instrumento de transformação, onde por meio dos conhecimentos escolares, planejamento, currículo ação, oculto e avaliado são representados aos estudantes os elementos da cultura escolar, da política curricular nacional, ou

\footnotetext{
${ }^{1}$ Instituto Federal Catarinense (IFC), Camboriú - SC - Brasil. Pedagoga- Supervisora Educacional e Professora da área de Pedagogia do Instituto Federal Catarinense. Doutora em Educação pelo PPGE da Universidade Federal de Santa Catarina, Linha de Pesquisa: Ensino e Formação de Professores. ORCID: <https://orcid.org/0000-00028176-1930>. E-mail: andressabrandt@hotmail.com

${ }^{2}$ Instituto Federal Catarinense (IFC), Camboriú - SC - Brasil. Professora nos cursos de licenciatura e no Programa de Pós-graduação em Educação Lato Sensu. Coordenadora do Programa de Pós-graduação em Educação Lato Sensu do Instituto Federal Catarinense - Campus Camboriú. Coordenadora pro tempore do Curso de Mestrado em Educação. Doutora em Educação pela Universidade Federal de Santa Catarina. ORCID: <https://orcid.org/00000002-8275-7714>.E-mail: filomena.silva@ifc.edu.br

${ }^{3}$ Instituto Federal Catarinense (IFC), Camboriú - SC - Brasil. Professora e pesquisadora com experiência na área de Educação Básica e Superior. Doutora em Educação pela Universidade do Vale do Rio dos Sinos. ORCID: <https://orcid.org/0000-0001-6788-6238>.E-mail: sonia.fernandes@ifc.edu.br

${ }^{4}$ Universidade Estadual do Maranhão (UEMA), São Luís - MA - Brasil. Professora da. Integrante do Grupo de Pesquisas Interdisciplinares: Educação, Saúde e Sociedade (UEMA/CNPq). Doutora em Educação pela UFRN. ORCID: <https://orcid.org/0000-0001-6956-4670>.E-mail: franclanecarvalhon@ gmail.com

5 Universidade Federal de Pelotas (UFPEL), Pelotas - RS - Brasil. Doutoranda em Educação. ORCID: <https://orcid.org/0000-0003-1349-4487>.E-mail: nadjamagalhaes78@gmail.com

${ }^{6}$ Universidade Estadual de Campinas (UNICAMP), Campinas - SP - Brasil. Doutorando em Educação. ORCID: <https://orcid.org/0000-0003-1893-1316>. E-mail: joelsonmorais@ hotmail.com
} 
seja, faz parte do currículo todos os elementos de um desenvolvimento curricular, os quais são imbricados pela cultura.

PALAVRAS-CHAVE: Currículo. Cultura. Cultura escolar. Licenciatura em pedagogia.

RESUMEN: El propósito de este estudio es analizar las representaciones que los estudiantes de una Licenciatura en Pedagogía de un Instituto Federal (IF) del Estado de Santa Catarina tienen en cuenta en un plan de estudios y sus implicaciones en las políticas curriculares de la Educación Básica. En esta investigación de carácter cualitativo, utilizamos como método una entrevista semiestructurada con preguntas abiertas como instrumento de cola de información, así como también con 08 estudiantes de pregrado de los semestres $7^{\circ}$ y $8^{\circ}$ del curso referido. Los resultados muestran que las percepciones de dos graduados se basan en la comprensión del currículo como un instrumento de transformación, en dos niveles de la escuela, la planificación, el currículo, ocultos y evaluados, ya sea que estén representados por estudiantes o elementos de la cultura escolar, o por la política curricular nacional, seja, parte del currículo, todos los elementos de un desarrollo curricular, quais são imbricados pela cultura.

PALABRAS CLAVE: Currículo. Cultura. Cultura escolar. Licenciatura en pedagogía.

ABSTRACT:The purpose of this study is to analyze the representations that students of a Bachelor's Degree in Pedagogy of a Federal Institute (IFs) of the State of Santa Catarina possuem em relação a compreensão do conceito de curriculum and suas implicações nas curriculum policies of Basic Education. In this research of qualitative character, we use as a method semi-structured interview with open questions as an instrument of information queue, as well as conducted with 08 undergraduate students of the 7th and 8th semesters of the referred course. The results show that the perceptions of two graduates are based on curriculum comprehension as an instrument of transformation, on two levels of school, planning, curriculum, hidden and evaluated, whether they are represented by students or school culture elements, or by national curricular policy, seja, part of the curriculum, all elements of a curricular development, quais são imbricados pela cultura.

KEYWORDS: Curriculum. Culture. School culture. Bachelor in pedagogy.

\section{Contextualização introdutória}

No contexto atual da sociedade brasileira que sofre com a crise política e com a imposição de reformas educacionais como a Reforma do ensino médio aprovada por meio da Lei $n^{\circ}$ 13.415/2017; à Emenda Constitucional n 95/2016, que torna de difícil concretização as metas e estratégias do Plano Nacional de Educação 2014-2024, pois congelou os gastos sociais em educação e saúde; a reforma trabalhista que causa retrocessos aos direitos historicamente conquistados pela classe trabalhadora desse país; a reforma da previdência em tramitação no Congresso Nacional que acaba com a aposentadoria integral dos trabalhadores; e a reforma 
política que vias de ser aprovada, há uma forte ressignificação de normas, valores e consequentemente da cultura da nação brasileira.

Com base nessas proposições, afirma-se que o conceito de cultura e sua implicação na cultura escolar é um tema contemporâneo e complexo de ser definido, pois sua constituição está em constante transformação, é algo dinâmico, por estar em constante modificação por meio das relações humanas, que modificam o significado de cultura a cada processo de interação.

Considera-se a existência de um poder simbólico de dominação cultural em busca das relações de poder que estão diretamente relacionadas com as questões econômica, sociais, políticas, ou seja, culturais de dominação de uma determinada sociedade, as quais, refletem diretamente na educação e consequentemente na cultura de uma nação e na cultura escolar proposta e implementada nas escolas.Com base nessa proposição afirmamos que o capital cultural imposto pelos agente internacionais e multilaterais, refletem diretamente na cultura escolar, ou seja, nos conhecimentos que tornam-se valiosos nas propostas curriculares, nas reformas educacionais, nos currículos das instituições educacionais para dar conta dos interesses neoliberais.

Nesse cenário, o conceito de cultura é um dos elementos fundante da pesquisa que tem como objetivo principal avaliar a política curricular produzida em âmbito nacional e local e seus impactos sobre os sistemas educacionais das redes públicas catarinenses para através do estudo deste conceito identificar a herança simbólica acumulada historicamente e que influencia de forma direta a constituição das políticas curriculares, no âmbito nacional, do Estados e de seus municípios.

Os esforços de definir cultura então centrados no campo da sociologia, da filosofia e da antropologia, neste sentido, há séculos a humanidade tenta definir e discutir a concepção de cultura, onde os estudos são intensificados na relação entre os povos e nações com diferentes culturas. Há uma grande dificuldade no campo de definir cultura, pois a evolução humana traz novos significados, pois "tudo que é cultural é humano, e tudo que é humano é cultural" (SANTOS, 2006, p. 29), ocasionando uma concepção ampla e de complexa definição ou seja, sem os homens não haveria cultura, assim como, sem a cultura, não haveria homens (GEERTZ, 1989).

Cultura é um dos conceitos referência para o projeto educacional do país, por isso faremos um esforço para compreender seus significados e seu processo de evolução conceitual de acordo com a evolução da humanidade. Nesse aspecto, em relação a cultura, corroboramos como Geertz (1989), o qual compreende a cultura como um protótipo historicamente 
perpassado de significados, os quais são herdados e transmitidos através de um sistema de concepções simbólicas, por meio das quais, os homens estão inseridos em um contexto social, no qual desenvolvem o seu conhecimento e seu modo de viver pautados na cultura que herdam e modificam em contato com a sociedade.

Neste sentido, autores como Santos (2006) e Geertz (1989), possuem uma aproximação conceitual em relação a cultura, pois ambos possuem a acepção que a cultura não pode ser meramente compreendida como padrões culturais herdados dos antepassados, ou seja, de costumes, tradições e hábitos. Os mesmos autores defendem que a cultura é fortemente influenciada pelas relações de poder que que se estabelecem entre os seres humanos, nas nações que estão inseridos, sendo desta forma, algo que fomenta a engrenagem social de controle do comportamento e instruções dos sujeitos, onde a cultura é fomentada pelo sistema de controle simbólico constituído nessas relações de controle e poder.

Nesse contexto que, na concepção de Geertz (1989), o estudo da cultura está fundamentado na análise e na interpretação pela sociedade dos códigos simbólicos herdados e compartilhados pelos homens que são membros e constituem uma determinado agrupamento social que produz e (re)significa os processos culturais de seu grupo nos processos de relação constituídos entre os mesmos, pois, a cultura é produzida historicamente, são as "transformações ocorridas no tempo, as rupturas ou as continuidades consolidadas em uma determinada sociedade (LARAIA, 2003).

Essa afirmação, suscita várias questões: Quais elementos culturais estão contemplados nas políticas curriculares dos estados brasileiros? Que conhecimentos e conteúdos são considerados valiosos para a formação cultural dos educandos que frequentam as escolas públicas brasileiras? Que fatores políticos, econômicos, educacionais, grupos culturais e sociais foram considerados na formulação o nas políticas curriculares do país? Que fatores políticos, econômicos, educacionais, grupos culturais e sociais conseguiram exercer influência na formulação e na implantação das reformas educacionais em implementação nas escolas públicas dos estados brasileiros? As atuais propostas curriculares dão conta da diversidade e diferenças culturais presentes na sociedade contemporânea? Como a escola relaciona-se com o espaço de cruzamento de culturas diferentes, com os conflitos e diálogos que se estabelecem nessa interpelação? O que prevalece nas políticas curriculares e consequentemente nos conteúdos curriculares das escolas é uma visão monocultural ou multicultural?

Assevera-se que há a consciência do desafio que está presente na tentativa de conceituar cultura e sua relação estreita com a educação, escola e consequentemente com a cultura escolar 
pela diversidade de abordagens teóricas utilizadas na sua definição e na identificação das práticas que a materializam. Neste sentido, corrobora-se que a seguinte afirmação: a centralidade da cultura advém, em grande medida, da transformação das esferas tradicionais da sociedade, econômica, social, política e cultural e tem enorme impacto de transformação do cotidiano (HALL, 1997).

Portanto, o presente texto tem como objetivo delinear os conceitos de cultura e cultura escolar enquanto elementos/categorias constituintes do conceito de currículo. Nessa direção, o texto está organizado em três seções, a saber: i) alguns aspectos da fundamentação teórica de cultura; ii) alguns aspectos sobre o conceito de cultura escolar; iii) percepção dos licenciandos sobre o conceito de currículo e alguns aspectos de sua fundamentação teórica. Desta maneira, pretende-se apresentar a seguir fundamentações e análises desenvolvidas referentes as vozes dos sujeitos pesquisados.

\section{Alguns aspectos sobre o conceito de cultura}

O conceito de cultura e sua implicação nas culturas escolares é contemporâneo e complexo de ser definido. Seus processos culturais em termos de produção, reconhecimento, acesso, socialização, integração, etc., estão em constante transformação; é dinâmica por envolver relações humanas e processos de interação. No âmbito escolar, ao se pensar qualquer forma de organização e materialização das trajetórias formativas se leva em conta que as culturas que se constituem daquilo que denominamos 'ser humano'.

Na contemporaneidade e em um país tão grandioso como o Brasil, definir o que é cultura se torna uma tarefa complexa ao mesmo tempo desafiadora, principalmente por que ela está em constante transformação e influencia fortemente a educação, contexto esse que interessa na presente pesquisa.

No caso específico da sociedade brasileira, os portugueses, os espanhóis, os africanos escravos que aqui chegaram, os indígenas que já habitavam as terras brasileiras antes da chegada dos portugueses, são os povos que representam a matriz da cultura do nosso povo, mas não podemos deixar de destacar que a cultura brasileira vai se modificando pela influência de outros povos, linguagens, grupos sociais que vão se constituindo nas relações sociais.

Conforme Santos (2006), a epistemologia da palavra cultura tem origem latina e em seu significado original está ligada às atividades agrícolas. Vem do verbo latino colere, que quer dizer cultivar. Pensadores romanos antigos ampliaram esse significado e a usaram para se referir 
ao refinamento pessoal, e isso está presente na expressão cultura da alma. Para o mesmo autor, “como sinônimo de refinamento, sofisticação pessoal, educação elaborada de uma pessoa, cultura foi usada constantemente desde então e é até hoje" (SANTOS, 2006, p.27).

As preocupações com cultura se voltaram tanto para a compreensão das sociedades modernas e industriais quanto das que iam desaparecendo ou perdendo suas características originais em virtude daqueles contatos. Contudo, toda essa preocupação não produziu uma definição clara e aceita por todos do que seja cultura. Portanto, para Santos (2006, p.21-22), "por cultura se "entende muita coisa", e a maneira como falei dela nas páginas anteriores é apenas um entre muitos sentidos comuns de cultura".

Para o antropólogo contemporâneo Geertz (1989), a cultura é um conceito que não pode ser definido em um parágrafo ou em uma obra, e sim algo que deve ser percebido e não algo que deve ser definido, onde as classificações são algo superficial, pois não é propriedade, e sim um grande mecanismo de significados que podem ser identificados de forma material ou imaterial, em uma manifestação ou no teatro, está amplamente ligada as linguagem e o que dá significado aos serem humanos. Onde cultura é tudo aquilo que é transmitido e recebido, ou seja, compartilhado na sociedade, pois a cultura não é estática, ela está em constante transformação na troca de significados entre os sujeitos que se relacionam em determinado contexto social.

Segundo Santos (2006), a cultura pode ser compreendida de diversas formas, pois, derivam de um conjunto comum de preocupações, podendo ser definida em duas concepções básicas: "a primeira concepção de cultura remete a todos os aspectos de uma realidade social; a segunda refere-se mais especificamente ao conhecimento, às ideias e crenças de um povo" (SANTOS, 2006, p. 23).

Caminhou-se dessa maneira para consolidar as modernas preocupações com cultura, procurando dar conta sistematicamente de uma diversidade de maneiras de viver que já havia sido motivo de reflexão por séculos. Observem, porém, que se essa preocupação já existia, a palavra cultura percorreu um longo caminho até adquirir esse sentido. Nesse aspecto, "a cultura é um aspecto de nossa realidade e sua transformação, ao mesmo tempo a expressa e a modifica (SANTOS, 2006, p. 79).

Evidentemente, os padrões culturais não são imutáveis, mas têm determinadas continuidades em seu processo de transformação. Assim, as reflexões a respeito da cultura servem para compreendê-la no cerne de um campo de forças entre o instituído, que representa os valores, os símbolos, os códigos e as normas estabelecidas e o instituídas, que representa 
aquilo que ainda está em processo de institucionalização. Desse modo, o estudo sobre a cultura possibilita a reflexão a respeito da relação dialética entre essas duas dimensões e a identificação da força cultural de determinados valores, suas interfaces, variações e mutações em um determinado contexto social (CHAUI, 2001a).

De modo que, no estudo da cultura em nossa sociedade, valem as mesmas observações feitas anteriormente em relação ao relativismo. Observem que vivemos numa sociedade que tem uma classe dominante, cujos interesses prevalecem. Se fôssemos relativizar os critérios culturais existentes no interior da sociedade acabaríamos por justificar as relações de dominação e o exercício tradicional do poder: eles também seriam relativos (SANTOS, 2006, p. 20).

No estudo de culturas de sociedades diferentes quanto das formas culturais no interior de uma sociedade, mostrar que a diversidade existe não implica concluir que tudo é relativo, apenas entender as realidades culturais no contexto da história de cada sociedade, das relações sociais dentro de cada qual e das relações entre elas. (SANTOS, 2006, p. 20). Nem tudo que é diverso o é da mesma forma. Não há razão para querer imortalizar as facetas culturais que resultam da miséria e da opressão. (SANTOS, 2006, p. 20). Afinal, as culturas movem-se não apenas pelo que existe, mas também pelas possibilidades e projetos do que pode vir a existir (SANTOS, 2006, p. 20).

Em geral, para se analisar o conjunto da formação cultural de uma determinada sociedade representada pelos símbolos, rituais, crenças e valores historicamente herdados, bem como validados e repletos de sentido a ponto de influenciar e dominar o conjunto das atitudes e representações dos agentes sociais constitui-se o que os antropólogos denominam identidade social, os quais interferem diretamente no processos de educação dos homens na sociedade. Para Ghiraldelli Jr. (2009, p. 13):

O termo educação tem sua origem em duas palavras do latim: educere e educare. A primeira quer dizer "conduzir de fora', "dirigir exteriormente'; a segunda indica "sustentar", "alimentar", "criar". O sentido comum é de "instruir", mas como conotações diferentes que já indicam posturas pedagógicas diferentes. A derivação dupla da palavra deixa entrever dois grandes caminhos da filosofia da educação no mundo ocidental: por um lado, o ensino baseado em regras exteriores em relação ao aprendiz, por outro, o ensino dirigido no sentido de incentivar o aprendiz a forjar as suas próprias regras.

Neste sentido, o ser humano ao pautar suas ações nas regras e valores instituídos socialmente, está submetido aos padrões culturais impostos, mas ao subverter e recriar seus sentidos simbólicos, acaba a produzir outros significados culturais, ou seja, produz diferentes 
linguagens culturais e (re)significa os padrões culturais herdados socialmente. Destaca-se, porém que a distribuição do capital cultural nos processos de ensino, muitas vezes não ocorre de forma homogênea no interior dos processos educativos oferecidos as classes sociais de uma nação e que há um poder simbólico que busca a esforço da reprodução da cultura dominante, em detrimento de outras culturas.

Conforme Santos (2006), a moderna preocupação com cultura tem sua gênese associada tanto a necessidades do conhecimento quanto às realidades da dominação política, pois faz parte tanto da história do desenvolvimento científico quanto da história das relações internacionais de poder, por isso, quando conceituamos cultura há uma estrita relação com o próprio entendimento moderno do que seja uma nação tem muito a ver com as discussões sobre cultura.

Pode-se entender cultura como uma dimensão do processo social e utilizá-la como um instrumento para compreender as sociedades contemporâneas. "O que não podemos fazer é discutir sobre cultura ignorando as relações de poder dentro de uma sociedade ou entre sociedades" (SANTOS,2006, p. 80).

Para Geertz (1989), a cultura é constituída por um controle simbólico, conduzida pelas relações de poder instituídas em determinada nação e sociedade, por tanto, não podemos de forma simplista e ingênua dividir a cultura em erudita, popular e de massa, sem analisar as relações de força, de poder e simbólica que está por traz desse processo de produção e (re)significação da cultura na evolução da humanidade. Portanto, a cultura não pode ser vista como normas, hábitos e tradições de determinada sociedade, pois há códigos e símbolos sociais que são constantemente herdados, descobertos, criados e recriados de acordo com padrões históricos constituídos há séculos pela humanidade. Neste sentido, para Bourdieu (2014), a cultura é a concepção explicita de composição de uma estruturação simbólica do poder.

De acordo com Santos (2006), o estudo da cultura exige que se considere a transformação constante por que passam as sociedades, uma transformação de suas características e das relações entre categorias, grupos e classes sociais no seu interior. Além disso, "a cultura é um produto da história coletiva por cuja transformação e por cujos benefícios as forças sociais se defrontam" (SANTOS, 2006, p. 81).

Portanto, na perspectiva do mesmo autor (2006), para a compreensão da nossa realidade cultural é fundante entender o processo histórico que a produz, os muitos caminhos que conduziram os grupos humanos às suas relações presentes e suas perspectivas de futuro, também as relações de poder e o confronto de interesses dentro da sociedade. Destaca-se que 
esses processos não são lineares e nem estanques, pois “a cultura é uma preocupação contemporânea, bem viva nos tempos atuais" (SANTOS, 2006, p. 7).

Corrobora-se com Santos (2006, p. 8), ao expressar que a cultura diz respeito à humanidade como um todo e ao mesmo tempo a cada um dos povos, nações, sociedades e grupos humanos. Quando se considera as culturas particulares que existem ou existiram, logo se constata a grande variação delas. Pois, a história registra com abundância as transformações por que passam as culturas, sejam movidas por suas forças internas, sejam em consequência desses contatos e conflitos.

Ao se discutir sobre o conceito de cultura é importante ter sempre em mente a humanidade em toda a sua riqueza e multiplicidade de formas de existência, onde é perspicaz relacionar a variedade de procedimentos culturais com os contextos em que são produzidos. Segundo Santos (2006, p. 9):

$\mathrm{Na}$ verdade, se a compreensão da cultura exige que se pense nos diversos povos, nações, sociedades e grupos humanos, é porque eles estão em interação. Se não estivessem, não haveria necessidade nem motivo nem ocasião para que se considerasse variedade nenhuma. A riqueza de formas das culturas e suas relações falam bem de perto a cada um de nós, já que convidam a que nos vejamos como seres sociais, nos fazem pensar na natureza dos todos sociais de que fazemos parte, nos fazem indagar sobre as razões da realidade social de que partilhamos e das forças que as mantêm e as transformam.

Logo, compreender a constituição da cultura, como artefato que está em constante transformação e essa mudança é fundante para a produção cultural, a partir da reflexão sobre como tratar a dimensão cultural em nossa própria sociedade, considerando que a cultura é a dimensão do processo social dinâmico. Para Santos (2006, p. 44-45):

A cultura é uma construção histórica, seja como concepção, seja como dimensão do processo social. Ou seja, a cultura não é "algo natural", não é uma decorrência de leis físicas ou biológicas. Ao contrário, a cultura é um produto coletivo da vida humana. Isso se aplica não apenas à percepção da cultura, mas também à sua relevância, à importância que passa a ter. Aplicase ao conteúdo de cada cultura particular, produto da história de cada sociedade. Cultura é um território bem atual das lutas sociais por um destino melhor. E uma realidade e uma concepção que precisam ser apropriadas em favor do progresso social e da liberdade, em favor da luta contra a exploração de uma parte da sociedade por outra, em favor da superação da opressão e da desigualdade.

Neste sentido, o estudo da cultura contribui no combate a preconceitos, oferecendo uma plataforma firme para o respeito e a dignidade nas relações humanas, as discussão sobre cultura pode nos ajudar a pensar sobre nossa própria realidade social e refletir sobre suas desigualdades 
para buscar transpor esses processos desiguais perante as diferenças culturais que há em um país tão extenso como o nosso Brasil.

Portanto, de acordo com Santos (2006), as preocupações com cultura surgiram associadas ao progresso da sociedade e do conhecimento quanto a novas formas de dominação, onde as próprias preocupações com cultura são instrumentos de conhecimento, respondem a necessidades de conhecimento da sociedade, as quais se desenvolveram claramente associadas com relações de poder. Hoje em dia os centros de poder da sociedade se preocupam com a cultura, procuram defini-la, entendê-la, controlá-la, agir sobre seu desenvolvimento. "Expressam seus conflitos e interesses, e nelas os interesses dominantes da sociedade manifestam sua força" (SANTOS, 2006, p. 17-18).

Nesse sentido, percebe-se que as preocupações com a cultura mantêm sua proximidade com as relações de poder. Continuam associadas com as formas de dominação na sociedade, e continuam sendo (SANTOS, 2006, p. 82).

Assim, sem a intenção de atender a gama de concepções e vertentes que conceituam a "cultura" tentou-se de forma singela fazer uma análise do que vem sendo discutido em relação aos processos de constituição, reprodução e ressignificação do capital cultural de uma determinada sociedade onde instrumentos de conhecimento e do capital cultural estão diretamente ligados ao progresso social, onde "as lutas pela universalização dos benefícios da cultura são ao mesmo tempo lutas contra as relações de dominação entre as sociedades contemporâneas, e contra as desigualdades básicas das relações sociais no interior das sociedades. Desta forma, a "cultura é o legado comum de toda a humanidade" (SANTOS, 2006, p. 86).

\section{Aspectos acerca da definição de cultura escolar}

Definir e mapear a cultura escolar é algo complexo, pois envolve vários aspectos da prática educativa e do currículo. Assevera-se que os conhecimentos dominantes na cultura escolar são escolhidos e planejados pela cultura dominante, do contexto político, econômico, social e cultura e educacional de uma sociedade, pois busca sempre a dominação simbólica da cultura dominante, escolhendo alguns aspectos culturais e detrimento de outros, questões essas que influenciam diretamente as políticas curriculares de um país e de seus estados. Esse contexto, nos faz pensar sobre: que capital cultural está sendo valorado aos estudantes por meio das políticas curriculares e reformas educacionais brasileiras? 
De acordo com Barroso (1996), o conceito de cultura escolar tem sido utilizado para pôr em evidencia a função da escola como transmissora de uma cultura específica no quadro do processo de socialização e integração nacional das crianças e dos jovens. Por isso, é fundante a conceituação de cultura escolar, no sentido de identificar no estudo proposto do observatório qual é a perspectiva (funcionalista, estruturalista e interacionista) em relação a "cultura escolar" que compreendemos e assumimos enquanto grupo de pesquisa.

Com esse fim, segundo Barroso (1996), os estudos sobre a escola deverão ter em linha de conta as três dimensões essenciais do processo de referencialização da cultura organizacional: as normas, as estruturas e os atores. Onde o princípio da homogeneidade (das normas, dos espaços, dos tempos, dos alunos, dos professores, dos saberes e dos processos de inculcação) constitui uma das marcas mais distintivas da "cultura escolar".

Segundo o mesmo autor (1996), e está "vida própria" é "este apoiar se sobre o passado" das instituições escolar que explica, igualmente, que as tentativas de mudança normativa da instituição escolar, determinadas pelo poder político através de reformas, tenham tido tão pouco sucesso. Torna-se, por isso, necessário analisar as diferentes dimensões da cultura escolar tendo princípios gerais da administração escolar em conta, entre outros fatores, a diversidade de abordagens teóricas utilizadas na sua definição e a identificação das práticas que a materializam.

Segundo Barroso (1996), pode-se dizer que é possível identificar três tipos de abordagens para a definição de cultura escolar: Na perspectiva funcionalista, a "cultura escolar" é a Cultura (no seu sentido mais geral) que é veiculada através da escola. A instituição educativa é vista como um simples transmissor de uma Cultura que é definida e produzida exteriormente e que se traduz nos princípios, finalidades e normas que o poder político (social, econômico, religioso) determina como constituindo o substrato do processo educativo e da aculturação das crianças e dos jovens. Como exemplo de autores que consideram a cultura escolar na perspectiva funcionalista temos Chervel (1998); e Julia (1995).

$\mathrm{Na}$ perspectiva estruturalista, a "cultura escolar" é a cultura produzida pela forma escolar de educação, principalmente através da modelização das suas formas e estruturas, seja o plano de estudos, as disciplinas, o modo de organização pedagógica, os meios auxiliares de ensino; E na perspectiva interacionista, a “cultura escolar" é a cultura organizacional da escola. Neste caso, não se fala da Escola enquanto instituição global, mas sim de cada escola em particular. O que está em causa nesta abordagem é a "cultura" produzida pelos atores organizacionais nas relações uns com os outros, nas relações com o espaço e nas relações com os saberes. 
Ao considerar-se as três abordagens teóricas utilizadas na sua definição de cultura escolar, se compreende a complexidade da sua definição de acordo com cada abordagem teórica. Portanto, na atualidade também não se pode negar que a escola não é a única forma de transmissão de cultura, essa também se estabelece nas relações familiares, na sociedade, nos espaços religiosos e é fortemente transmitida pelos meios de comunicação, pelos grupos sociais, estes que estão em constante processo de produção cultural e ao mesmo tempo em uma ampla dinâmica de transformação e produção de cultura, a qual não é estanque, pois se modifica constantemente em cada relação humana que se estabelece nos sociedades. Nesse processo ativo de produção e (re)significação da cultura, Hall (1997), assevera que “(...). Por bem ou por mal, a cultura é agora um dos elementos mais dinâmicos e mais imprevisíveis, da mudança histórica do novo milênio" (HALL, 1997, p. 20).

Corrobora-se com os autores como Chervel (1998) e Barroso (1996), que afirmam que não podemos acreditar que a escola é mera reprodutora de sua cultura escolar, ela também produz sua própria cultura de forma dinâmica e autônoma. Entende-se, portanto, que "A escola, nesse contexto, mais que a transmissora da cultura, da verdadeira cultura, passa a ser concebida como um espaço de cruzamento, conflitos e diálogo entre diferentes culturas por diversos grupos sociais" (MOREIRA; CANDAU, 2003, p. 161).

Os seres humanos são seres interpretativos que produzem cultura enquanto se constituem como sujeitos. Assim, a cultura sempre foi importante para as ciências humanas e sociais, e a pouco tempo vem sendo discutida e reconhecida pela Educação. Para Hall (1997), afirma que são os códigos de significado que dão sentido às nossas ações na medida em que nos permitem interpretar significativamente as ações alheias e que, em seu conjunto, constituem nossas culturas. As afirmações de Hall (1997) nos auxiliam a pensar que toda ação social e cultural, já que todas as práticas sociais expressam um significado e, neste sentido, são práticas de significação.

A cultura está intrinsecamente ligada à educação, ao currículo, pois ela é vida por estar intrínseca na relação com o social, ou seja, na vivência humana, e na escola que ela é transmitida e (re)significada constantemente nas relações pedagógicas que se constituem no espaço escolar. Pérez Gómez (1998), propõe que entendamos hoje a escola como um espaço de "cruzamento de culturas", sendo importante que sejamos capazes de identificar as diferentes culturas que se relacionam no contexto escolar e reconhecer as interações, o impacto que as diferentes culturas exercem continuamente em seu universo e seus atores. 
Conforme o mesmo autor (1998), a escola é o lugar de aprendemos e refletirmos sobre o complexo cruzamento de culturas que se produz nesse contexto educacional, por exemplo entre as propostas da cultura crítica, que se situa nas disciplinas científicas, artística e filosóficas; entre as determinações da cultura acadêmica, que se refletem no currículo; nas influências da cultura social, constituídas pelos valores hegemônicos do cenário social; as pressões cotidianas da cultura institucional, presente nos papéis, normas, rotinas e ritos próprios da escola como instituição social específica; e as características da cultura experiencial, adquirida por cada aluno através da experiência dos intercâmbios espontâneos com seu entorno.

Desse modo, compreende-se que as práticas sociais desenvolvidas na/pela escola são basilares para o entendimento da cultura escolar, particularmente no que se refere à sua forma de organização, seleção de conteúdos curriculares e ao desenvolvimento de relações interpessoais, assim como os discursos e as formas de comunicação e de linguagens, presentes no cotidiano escolar, constituem um aspecto fundamental de sua cultura. Nesse direcionamento, Forquin (1993), afirma que há uma forte intersecção entre educação e cultura, como uma relação íntima e orgânica. Neste sentido, o mesmo autor afirma que:

A palavra "educação" no sentido amplo, de formação e socialização do indivíduo, quer se restrinja unicamente ao domínio escolar, é necessário reconhecer que, se toda a educação é sempre educação de alguém, por alguém, ela supõe também, necessariamente a comunicação, a transmissão, a aquisição de alguma coisa: conhecimentos, competências, crenças, hábitos, valores, que constituem o que se chama precisamente de "conteúdo" da educação. Devido ao fato de que este conteúdo parece irredutível ao que há de particular e contingente na experiência subjetiva ou intersubjetiva imediata, constituindo, antes, a moldura, o suporte e a forma de toda experiência individual possível, devido, então, a que este conteúdo que se transmite na educação é sempre alguma coisa que nos procede, nos ultrapassa, nos institui enquanto sujeitos humanos, pode-se perfeitamente dar-lhe o nome de cultura. (FORQUIN, 1993, p. 10).

Desse modo, o currículo prescrito é fomentado pelos interesses da classe a dominante que exerce forte influência através do seu poder simbólico e consequentemente produz o capital cultural que é contemplado nas escolas, sobre, portanto as políticas curriculares e as reformas educacionais muitas vezes são resultados de um processo que reflete, predominantemente, os interesses particulares da uma dinâmica que não tem valorizado os diferentes e diversos interesses culturais presentes na escola. Portanto, à escola, tem importante papel na a análise das concepções pedagógicas presentes do currículo escolar prescrito, no currículo realizado e no currículo oculto presente na transmissão e reprodução da cultura escolar. 
$\mathrm{Na}$ visão estruturalista a cultura escolar pode ser compreendida como um conjunto de práticas, normas, ideias e procedimentos, que resistem ao tempo, que se expressam em modos de fazer e pensar o cotidiano da escola e para autores como Viñao Frago ( 2000), são esses modos de fazer e de pensar, atitudes, rituais, mitos, discursos, ações, amplamente compartilhados, assumidos, servem a uns e a outros para desempenhar suas tarefas diárias, entender o mundo educativo e fazer frente tanto às mudanças ou reformas como às exigências de outros membros da instituição.

Acredita-se, porém, que a cultura escolar não é estanque e se manifesta para além do que e proposto conceitualmente por Viñao Frago e assevera-se que na atualidade o currículo realizado é processual ao estabelecer um diálogo entre agentes sociais, elementos técnicos, alunos que reagem frente a ele, professores que o modelam (SACRISTÁN, 1998). Entretanto, é uma reflexão das situações sociais educacionais e políticas presentes no cotidiano do aluno para a partir daí selecionar as contribuições que beneficie e solucione determinados problemas.

É impossível desconsiderar, ou nos dizeres de Forquin (1993), é injustificável desconsiderar a diversidade de identidades socioculturais existentes na escola. Neste sentido, esboçamos que também nos interessa olhar se nas políticas curriculares que norteiam os currículos das escolas públicas catarinenses há uma orientação multiculturais e emancipatórias nas práticas educativas.

Neste sentido, a cultura é uma questão de destaque contemporâneo, pois transformouse em um dos elementos mais dinâmicos e imprevisíveis das mudanças históricas na contemporaneidade (MOREIRA; CANDAU, 2014).

Contemporaneamente, as muitas exclusões operadas pela criação de uma cultura geral estão sendo postas em xeque, o que não significa que tenham deixado de ocorrer. As mudanças tecnológicas aproximando os sujeitos no espaço e no tempo, a globalização econômica, o fim da Guerra Fria, os fluxos migratórios são alguns dos ingredientes que criam uma atmosfera favorável ao maior fluxo de pessoas entre culturas. Os movimentos sociais diversos - étnicos, de gênero, LGBT (lésbicas, gays, bissexuais, transexuais e transgêneros), religiosos - se juntam às críticas marxistas denunciando a exclusão de suas culturas dessa tal cultura geral. Essa cultura, de caráter universal, é posta em questão por sociedades que se mostram, a cada dia, mais multiculturais (LOPES; MACEDO, 2011, p. 185).

Por isso, acredita-se que atualmente no contexto social que vivencia-se há muitas diferenças que estão explicitas e os processos de mudança são dinâmicos, acarretando em atualização das práticas educativas, pois a cultura escolar também adapta-se as diferenças que 
fortemente influenciam os currículos das instituições escolares. Elementos esses, que para Forquin (1993), pela modernidade, levam a escola ter uma forte crise em relação a que conhecimentos ensinar diante do pluralismo cultural, das diferenças sociais, étnicas e religiosa, enfim que cultura transmitir e quais conteúdos valiosos precisam estar contemplados nos seus currículos. Em relação a essa questão, corrobora-se com o mesmo autor, ao defender que a escola deve trabalhar com o universalismo, ensinando aos educandos algo que tenha valor intrínseco, além de atender as demandas sociais imediatas.

Justifica-se, portanto, a seguinte reflexão: as políticas curriculares e as reformas educacionais implementadas nos estados brasileiros, oportunizam as escolas contemplar nos seus currículos a premissa que os conteúdos ensinados estão diretamente e exclusivamente atendendo os interesses e as reais necessidades dos estudantes pertencentes a realidade educacional de cada escola pública.

Autores do campo do currículo como Moreira (2014); Lopes e Macedo (2011), aceitam a centralidade da cultura, ou seja, que as práticas sociais envolvem produção de sentidos e mantém a postura de que o currículo precisa favorecer o reconhecimento das diferenças e o diálogo entre elas. Defende, assim, a contribuição do currículo para a construção de um mundo que aceite as diferenças, combate às desigualdades sociais, econômicas e o poder simbólico de dominação imposto pelo capital cultural dominante. Neste propósito, segundo Giroux (1992), no interior do currículo é fundante compreender como as relações nas quais as diferenças são construídas e operam como parte de um conjunto de práticas sociais, políticas e culturais são capazes de expressar e articular as diferenças no contexto das escolas.

Segundo Forquin (1993), currículo ao ser considerado um artefato cultural, o que implica nas suas determinações sociais da sua história, na sua produção contextual e emerge da relação escola e cultura escolar. Pois, o currículo prescrito e realizado é atravessado de valores, concepções, ideologias sociais e políticas, o qual se constitui em uma relação historicamente com os sujeitos sociais.

Os seres humanos são seres interpretativos que produzem cultura enquanto se constituem como sujeitos. A cultura sempre foi importante para as ciências humanas e sociais, e a pouco tempo vem sendo discutida e reconhecida pela Educação. Corrobora-se com Hall (1997), quando afirma que a cultura são os códigos de significado que dão sentido às nossas ações na medida em que nos permitem interpretar significativamente as ações alheias e que, em seu conjunto, constituem nossas culturas. As afirmações de Hall (1997), nos auxilia a pensar 
que toda ação social e cultural, já que todas as práticas sociais expressam um significado e, neste sentido, são práticas de significação.

Portanto, elucida-se que a aproximação dos debates intercultural com o campo do currículo já está posta, apresentando configurações específicas em diferentes áreas de conhecimento nos currículos das instituições educacionais. Neste sentido, "a cultura transformou-se, assim, em um dos elementos mais dinâmicos e imprevisíveis das mudanças históricas da contemporaneidade" (MOREIRA; CANDAU, 2014, p. 8).

E a atual cultura escolar e processos de aprendizagens que encontramos nas escolas não estão dão conta dessa variedade de culturas, crenças, valores que estão se relacionando no ambiente escolar. Neste sentido, assevera Moreira e Candau, que "tais questões refletem visões de cultura, escola, ensino e aprendizagem que não dão conta, a nosso ver, dos desafios encontrados em uma sala de aula "invadida" por diferentes grupos sociais e culturais, antes ausentes desse espaço.” (MOREIRA; CANDAU, 2003, p. 156).

Neste sentido, é complexo elucidar uma única vertente conceitual sobre a categoria cultura e cultura escolar pelas diversas vertentes que ela pode ser explicada. Enfim, busca-se a compreensão da articulação conceitual de cultura e cultura escolar, para avançar nas reflexões acerca das políticas curriculares para a Educação Básica nos estados brasileiros, seja na esfera municipal ou na estadual. Portanto, afirma-se ser significativo para a produção da cultura escolar os cruzamentos culturais que ocorrem no interior das escolas, mais especificamente na prática pedagógica que pões em ação o currículo prescrito, pois ocorrem na escola a interpelação entre os diferentes e diversos grupos sociais e culturais.

Pode-se afirmar, portanto, que a cultura e a cultura escolar são conceitos dinâmicos e complexos de definir. Assim, defende-se ser essencial considerar que a própria cultura é um motivo de conflito de interesses nas sociedades contemporâneas, e corroboramos com Santos (2006), ao afirmar que, em relação a conceituação de cultura há um conflito pela sua definição, pelo seu controle, pelos benefícios que pode assegurar as classes sociais que buscam através do poder simbólico a dominação de uma sociedade.

\section{Pressupostos metodológicos da pesquisa}

Esta pesquisa foi desenvolvida com estudantes do Curso de Licenciatura em Pedagogia de um instituto Federal da região Sul do país. Participaram do estudo 8 (oito) estudantes do $7^{\circ}$ e $8^{\circ}$ semestre de um curso de Licenciatura em Pedagogia de um Instituto Federal (IFs), do 
estado de Santa Catarina. Quanto aos aspectos éticos vinculados às pesquisas científicas, destaca-se que todos os estudantes aceitaram de forma espontânea realizar a pesquisa.

Para manter o anonimato dos interlocutores usamos um cognome, fazendo menção a nomes de artistas brasileiros de arte moderna, como: Tarsila do Amaral; Anita Malfatti; Di Cavalcanti; Inácio da Costa Ferreira; Vicente do Rego Monteiro; John Graz; Oswaldo Goeldi; Victor Brecheret.

Este estudo de caráter qualitativo auxiliou no entendimento dos pressupostos teóricos do campo do currículo. Usamos com método a entrevista semiestruturada com questões abertas. Cada interlocutor foi entendido como singular, tendo vista o contexto estudado. A entrevista semiestruturada (ANDRÉ, 1995), tem como objetivo, obter as impressões dos sujeitos da pesquisa sobre a conceituação de currículo para futuros professores da educação básica. A entrevista foi apresentada por escrito aos interlocutores.

O roteiro da entrevista foi elaborado a partir das demarcações do objeto de pesquisa, isto é, se estava relacionado com os objetivos primordiais, e as perguntas básicas foram as seguintes: 1) Qual é a sua compreensão do conceito de currículo? Que conhecimentos são valiosos e são impostos pelas forças dominantes na cultura escolar, por meio das políticas curriculares e reformas educacionais propostas pelos governos, ou seja, mais especificamente que conhecimentos são contemplados nos currículos das escolas de educação básica?

Com a análise de conteúdo se verifica os sentidos expressos pelos interlocutores. A análise de conteúdo seguiu as três etapas orientadas por Bardin (2009), que são: pré-análise; descrição e a interpretação inferencial. Os dois polos da análise de conteúdo são: a rigorosidade e a necessidade de ir além das aparências.

\section{O conceito de currículo e as impressões dos interlocutores da pesquisa}

Na concepção de Pacheco (2001, p. 19), o currículo é instrumento obrigatório para a análise e melhoria das decisões educativas, pois é uma construção permanente de práticas, com um significado marcadamente cultural e social.

Sobre a conceituação do currículo, Pacheco (2001, p. 15-16) nos diz:

O lexema currículo, proveniente do étimo latino correr, significa caminho, jornada, trajetória, percurso a seguir e encerra, por isso, duas ideias principais: uma de sequência ordenada, outra de noção de totalidade de estudos. Daqui a utilização do vocabulário currículo, do século XVII e nos países anglosaxônicos, para designar uma pista circular de atletismo, ou uma pista de percurso para carros de corrida de cavalos. 
Conforme o autor, no que tange ao sentido etimológico da palavra currículo, é importante percebemos os amplos sentidos que o conceito de currículo recebeu no decorrer da sua constituição histórica. Destaca-se que, durante o século XVII, nos países anglo-saxônicos, o termo era utilizado para caracterizar uma pista circular de atletismo ou uma pista de percurso para carros de corrida de cavalos. Estabelecendo uma comparação entre esta acepção e a atual, o termo currículo também é explicitado como programas de estudos, conjunto de experiências vividas pelos alunos na escola ou ainda, em um sentido mais abrangente, como projetos e diretrizes educacionais definidos pelas administrações centrais para serem adotados pelos sistemas de ensino.

Vê-se que o aporte teórico sobre o termo evidencia como os sentidos do currículo foram se modificando e se aprimorando, mas não perderam de todo essa conotação original, pois,

[...] a ideia de currículo como percurso de um conjunto de conhecimentos organizados e sistematizados está intimamente associada às mudanças sociais e econômicas da época pré-industrial, que trazem a necessidade de padronização e organização do ensino e da escola [...]. (LIMONTA, 2009, p. 118).

O significado do currículo é dado pelos próprios contextos em que se insere: contexto de aula; contexto pessoal e social; contexto histórico-escolar; contexto político. Desta forma, segundo a autora (2009), analisar currículos concretos significa estudá-los no contexto em que se configuram, em meio dos quais se expressa em práticas educativas e em resultados.

No entendimento de Sacristán (2000), todo modelo ou proposta de educação deve tratar explicitamente do referencial curricular e da realidade cultural de um país, o que tem relação com a significação dos conteúdos e dos usos dos currículos escolares. Neste sentido, para o mesmo autor (2000) a formação de educadores tem se constituído em uma das pedras angulares para qualquer intento de renovação do sistema educativo. Além disso, a atuação profissional dos professores está condicionada pelo papel que lhes é atribuído no desenvolvimento do currículo.

Na concepção de currículo como realidade social, construído no próprio processo, é preciso ver a função dos professores como mediadores pedagógicos, que filtram os condicionamentos culturais e profissionais para a mediação que realizam no processo educativo.

Percebe-se que na construção das práticas pedagógicas e no currículo escolar moldado pelos professores interferem diferentes fatores, os quais não podem ser ignorados no cotidiano 
escolar. Isso justifica a importância das discussões e dos estudos coletivos para a formulação da proposta curricular ou política pedagógica das instituições educativas. Neste sentido, toda proposta curricular é, por um lado, uma construção social e histórica; por um lado, pelos sistemas de controle social, político, administrativo, de inovação, conteúdos e materiais produzidos; por outro, pelos sistemas educativos, culturais, sociais, políticos e econômicos. Nesta perspectiva, Sacristán (2000, p. 102), assevera que:

Podemos considerar o currículo que se realiza a partir de uma série de práticas pedagógicas como o resultado de diversas influências convergentes e sucessivas, coerentes ou contraditórias, adquirindo, dessa forma, a característica de um ser-objeto preparado num processo complexo, que se transforma e se constrói nele próprio.

Por isso, exige ser avaliado não como um objeto estático, mas como a expressão de um equilíbrio entre múltiplos compromissos. E, mais uma vez, essa condição é crucial tanto para compreender a prática escolar vigente como para tratar de mudá-la.

Para Sacristán (2000, p. 103), a visão do currículo como algo que se constrói exige um tipo de intervenção ativa, discutida explicitamente em um processo de deliberação aberto por parte dos agentes participantes, professores, alunos, pais, forças sociais, grupos de criadores e intelectuais, a fim de que não se torne mera reprodução de decisões e modelações implícitas. Assim, não consideramos o currículo como algo tangível e nem os subsistemas que o determinam como realidades fixas, mas históricas.

Dessa forma, cabe destacar que o termo 'currículo' é complexo de conceituar em razão da sua dimensão política, social, cultural, econômica, administrativa, social e educacional. Está imbricado com um contexto histórico, e sua realização ocorre por sujeitos professores que mediatizam o processo de ensino-aprendizagem com os estudantes. Desse modo, o currículo é entendido "como uma dimensão política da educação, ou seja, como um instrumento que reflete quer as relações sempre existentes entre escola e sociedade, quer os interesses individuais e os de grupos, quer ainda os interesses políticos e ideológicos” (PACHECO, 2001, p. 19).

A compreensão do conceito de currículo é vasta e ampliada. Sacristán (2013, p. 34) destaca que hoje é possível observar diversos enfoques e concepções dispersos no campo curricular: "uma rápida busca do termo currículo em Google Books resulta em 60 (sessenta) mil resultados. A mesma busca na Biblioteca do Congresso dos EUA nos oferece mais de 9 (nove) mil resultados".

Estamos de acordo com Sacristán (2013), a respeito de serem são várias as peculiaridades que cercam o currículo, as quais pertencem a uma realidade complexa, difícil de 
explicar por meio de uma definição simples, esquemática e esclarecedora, devido à própria complexidade do conceito, tanto nos estudos sobre o tema quanto nos âmbitos práticos nos quais ele é projetado. Pois, para Pacheco (2001, p. 20), o currículo é uma prática pedagógica que resulta da interação e da confluência entre várias estruturas, na base das quais existem interesses concretos e responsabilidades compartilhadas.

Desta forma, também concorda-se que o currículo é a expressão cultural dos conteúdos das propostas curriculares e das práticas pedagógicas que as instituições educacionais tratam de difundir entre os estudantes que a frequentam, bem como os efeitos que os conteúdos provocam em seus receptores e em toda comunidade educacional, sendo, portanto, a expressão e a concretização do plano cultural que a instituição escolar torna concreto dentro da sua realidade e contexto social. "O campo em torno do currículo é um território de inevitável discussão." (SACRISTÁN, 2013, p. 11).

Compreende-se que no processo de desenvolvimento curricular, o aspecto da ação humana tem um valor fundamental; portanto, um currículo é realmente realizado pelo papel do professor na sua atuação pedagógica com os estudantes. Assim, a formação do professor contribui de forma positiva ou negativa na constituição do currículo escolar, pois é através dela que os professores alcançam as condições que lhes permitem refletir e discutir questões que influenciam sua atuação, ou seja, o processo de ensino-aprendizagem que realizam no contexto educacional.

No que diz respeito às forças que predominam no campo curricular, na acepção de Sacristán (2000, p. 16), o currículo, em seu conteúdo e formas, através das quais se apresenta aos professores e alunos, é uma opção historicamente configurada que se sedimentou dentro de uma determinada trama cultural, política, social e escolar. Está carregado, portanto, de valores e pressupostos que é preciso decifrar. Tarefa a cumprir tanto a partir de um nível de análise político-social quanto de sua instrumentação 'mais técnica', descobrindo os mecanismos que operam em seu desenvolvimento dentro dos campos escolares.

Na afirmação de Lopes e Macedo (2011), o currículo é uma produção cultural porque está inserido nessa luta pelos diferentes significados que conferimos ao mundo. O currículo não é um produto de uma luta fora da escola para significar o conhecimento legítimo, não é uma parte legitimada da cultura que é transposta para a escola, mas é a própria luta pela produção do significado.

Sabe-se que os currículos são a expressão do equilíbrio entre os interesses e as forças que gravitam ao redor do desenvolvimento de um determinado modelo curricular e de um 
sistema educativo, os quais são materializados no contexto escolar pela ação dos professores na realização do currículo em ação com seus estudantes e mediados pelo contexto social, econômico e cultural do local que estão inseridos.

Dessa forma, "não cabe falar em disputa pela seleção dos conteúdos, mas disputas na produção de significados na escola. Essa disputa não é restrita à escola, mas vincula-se a todo um processo social que tem a escola como um lócus de poder importante, mas que não se limita a ele" (LOPES; MACEDO, 2011, p. 93).

No tocante a essas questões, segundo Pacheco (2001), a política curricular é uma ação simbólica, representa uma ideologia para a organização da autoridade, que abrange tanto as decisões das instâncias políticas como as dos contextos escolares, as quais são implementadas por intermédio de instrumentos normativos explícitos e objetivos (leis, decretos-leis, portarias, despachos normativos, etc.), de atos normativos interpretativos e subjetivos (circulares e ofícios circulares) e também a partir de documentos de orientação e de apoio (textos de apoio, documentos internos da escola).

Desse modo, concorda-se que "o currículo que se realiza vem orientado por um plano cada vez mais global, cujos efeitos concretos dependem das condições nas quais se realiza" (SACRISTÁN, 2000, p. 97). As correlações de forças do CNE e das entidades educacionais receberam influências dos agentes de políticas educacionais nos âmbitos globais, nacionais e locais.

Quanto a essa questão, Sacristán (2000), assevera que a seleção cultural que o currículo deve compreender, assim como a sua elaboração pedagógica, exige um papel ativo muito importante por parte dos professores e uma formação em consonância com esse pressuposto, para que possa cumprir efetivamente a função educativa dentro da escolaridade obrigatória, a não ser que se preveja para eles uma atividade que consista em 'consumir' e desenvolver, em suas aulas, guias curriculares confeccionados por outros agentes exteriores, como as editoras.

Nesse sentido, quando questionados sobre a compreensão que possuem do conceito de currículo, tendo em vista a interlocução com o campo da cultura e cultura escolar, os estudantes responderam que:

Tarsila do Amaral - Currículo é um documento elaborado pela escola que visa nortear os conteúdos a serem trabalhados pela escola e professores. O mesmo é elaborado conforme documentos legais que norteiam a Educação. Portanto, é ensinado nas escolas o que está expresso nas diretrizes curriculares. 
John Graz - Currículo é um documento norteador, composto por um conjunto de ações, tem o objetivo de servir como instrumento de transformação e avaliação no âmbito escolar. O conteúdo ensinado é o que está escrito nos documentos legais.

Anita Malfatti - Currículo é orientar a sua trajetória. Pode ser também tradicional até mesmo oculto ou não. São os conteúdos que estão no Projeto Político Pedagógico de cada escola.

Inácio da Costa Ferreira - Entendo o currículo como a identidade da escola, onde nele é apresentado os valores e princípios que a escola irá passar, bem como os conhecimentos que será ensinado pela mesma, os objetivos que visa alcançar. O conteúdo ensinado é o oficial, poucas vezes se ensina a cultura da comunidade escolar.

Vicente do Rego Monteiro - Para mim o currículo compreende disciplinas, conteúdos a serem ensinados e também aprendidos, os quais, são determinados pelas propostas e políticas curriculares do Ministério da Educação para todos os estados brasileiros. Deve ser flexível [...].O currículo também pode e deve conter planos pedagógicos e projetos, bem como avaliações e resultados.

Di Cavalcanti - Currículo é apresentação, orienta sua trajetória, pode ser integrado, delimita a ação e propostas. Pode ser também ser tradicional, até mesmo existe o oculto e o fazer pedagógico. O conteúdo é o proposto pelas diretrizes curriculares da educação básica.

Oswaldo Goeldi - Currículo compreende todos os saberes específicos ou não, que são pré-estabelecidos de acordo com a grade da instituição. Também vai além, entende-se ao fazer e saber fazer de acordo com as necessidades que surgem ao longo do período estabelecido, deve ser muito bem planejado e executado para a melhor aprendizagem dos alunos. O conteúdo de um currículo da educação básica segue a cultura dominante, poucas vezes contempla a cultura popular.

Victor Brecheret - Currículo representa a organização dos saberes, o planejamento, a determinação dos conteúdos a serem disponibilizados nos espaços educacionais, a fim de concretizar os objetivos e os currículos instituídos pelo sistema educacional.

As respostas se diferenciaram, mas, em suma os estudantes acreditam que o currículo é um elemento de transformação da escola, por meio dos conhecimentos e conteúdos escolares, os quais são organizados pelos sistemas educacionais, são planejados e, materializados no currículo ação, no oculto e no avaliado, por meio dos elementos da cultura da sociedade e da cultura escolar. Nessa direção, organizando as diversas definições, acepções e perspectivas sobre currículo, Sacristán (2000), diz que este pode ser refletido e analisado através do ponto de vista de sua função social, como ponte entre a sociedade e a escola, e pelo projeto ou plano educativo, prescrito ou real, composto de diferentes aspectos, experiências e conteúdos. Para o autor, o currículo seria a expressão formal e material desse projeto, devendo apresentar, sob 
determinado formato, seus conteúdos, suas orientações e as sequências com que deve ser abordado.

Além disso, Sacristán (2000), afirma que os que exercem algum tipo de atividade discursiva acadêmica e de pesquisa entendem o currículo como um campo prático, o que supõe a possibilidade de: 1) analisar os processos instrutivos e a realidade da prática a partir de uma perspectiva que lhes dota de conteúdo; 2) estudar o currículo como território de inserção de práticas diversas, que não se referem apenas aos processos de tipo pedagógico, às interações ou às comunicações educativas; 3 ) sustentar o discurso sobre a interação entre a teoria e a prática em educação.

Dessa forma, o conceito de currículo desenvolve-se em diferentes fases do seu desenvolvimento. Mediatizado pelo contexto histórico, supõe a concretização dos fins sociais, culturais e de socialização que se atribui à educação escolarizada, com vertentes ideológicas e sociais. Recebe influência de agentes internos e externos, que o moldam de acordo com seus interesses e com as correlações de forças presentes em cada instituição educacional, e é constituído de três elementos essenciais: "de um propósito educativo planificado no tempo e no espaço em função de finalidades; de um processo de ensino-aprendizagem, com referência a conteúdos e atividades; de um contexto específico, o da escola ou organização formativa" (PACHECO, 2001, p. 90).

Para Contreras (1989), o currículo representa o conjunto das decisões educativas tomadas pelas instituições escolares. O currículo deve ser entendido como uma ferramenta conceitual que supõe sempre, de forma explícita ou tácita, uma resposta às perguntas: o que ensinar? Como e por quê? Portanto, o currículo vai se constituído desde o momento em que são publicados os documentos legais que sobre ele incidem até chegar àquilo que está expresso nas propostas pedagógicas e curriculares das escolas, alcançando também o resultado de sua avaliação e reformulação. Conforme assegura Limonta (2009, p. 107):

Daí a importância de se compreender o(s) significado(s) do currículo, uma vez que este será o definidor e organizador de conhecimentos e práticas que refletem uma concepção e um ideal de educação e que serão apropriados pelos graduandos, futuros professores. A resposta à pergunta "O que deve conter um currículo de um curso de formação de professores?" precisa considerar a multidimensionalidade do fenômeno educativo e ao mesmo tempo deve responder aos desafios históricos e emergentes e da Educação Básica brasileira e ao mesmo tempo constituir-se em elemento de resistência às concepções de formação aligeiradas e pragmáticas que têm sido impostas. 
Para finalizar, nos estudos referentes ao campo do currículo realizados pela pesquisadora, no tocante à busca por respostas para as perguntas propostas por Limonta (2007), destaca-se que entre os curriculistas existem conflitos de proposições e teorias referentes ao campo dos estudos do currículo, portanto há certa discordância instalada entre os intelectuais e entidades do campo. Avalia-se que tais conflitos sejam sadios, tendo em vista sua capacidade de conduzir a análises refinadas, voltadas para a criação de ideias que propiciem o avanço nos estudos curriculares, evitando que o conceito e as teorias de currículo assumam caráter incontestável, o que resulta na evolução e no aprimoramento deste campo de estudo.

\section{Considerações finais}

Em suma, os interlocutores ainda possuem uma pequena compreensão do campo curricular, o que é compreensível e justificado pelo que expusemos acima, ou seja, pelos distintos conceitos e perspectivas sobre currículo, os quais proporcionam diversas interlocuções e compreensões dos sujeitos da pesquisa.

Assim, compreende-se que o entrelaçamento de forças formais e informais resulta em uma política curricular e em um desenvolvimento curricular de formação, seja para a Educação Básica, seja para os cursos de formação inicial de professores. Essas políticas serão implementadas pelos professores e agentes educacionais em atuação nas instituições educacionais. Finalmente, evidencia-se que os processos de aprendizagem têm maior ou menor aceitação à medida que logram ou não atingir as finalidades dos currículos. Para Sacristán (2000), tais processos de aprendizagem, no que se refere a certos conteúdos, têm outros condicionamentos, advindos da atuação docente e, em geral, das condições ambientais escolares, os quais são caracterizados, nessa perspectiva, pelo currículo modelado e realizado pelos professores.

Nesse sentido, todo processo cultural explícito pelo currículo ocorre na instituição escolar, mediado pela prática pedagógica dos(as) professores(as) com os estudantes. Desta forma, acredita-se na importância do currículo para a formação cultural dos estudantes e para a cultura escolar e da escola, os quais, são influenciados também pelas práticas políticas, administrativas e institucionais, juntamente com o que costuma-se entender como genuína prática pedagógica, todas elas entrecruzadas no desenvolvimento do currículo. Nessa acepção, para Sacristán (2000), o projeto cultural se dá em um ambiente que, por si só, é elemento modelador ou mediatizador das aprendizagens e fonte de estímulos originais, independentes do 
próprio projeto cultural curricular, formando, em seu conjunto, o projeto educativo e socializador da instituição.

Além disso, a instituição educacional e o ambiente escolar que se cria sob suas condições compõem o currículo oculto, fonte de inumeráveis aprendizagens para o aluno. E é essa a derivação conceitual que se extrai, tal como vimos, ao enfocar-se o currículo como experiência ou como intersecção entre a teoria e a prática (SACRISTÁN, 2000, p. 91).

Assim, busca-se esclarecer a primeira premissa em relação ao conceito de currículo, que tem gerado grande confusão epistemológica e divergências, pela amplitude de definições e vertentes com que se pretende caracterizá-lo. Concorda-se que "o currículo, enquanto processo sistémico e deliberado, encerra em si uma complexidade tal que só será compreendida se analisadas as suas inúmeras coordenadas e vertentes" (PACHECO, 2001, p. 11). Pois, compreende-se o currículo como um movimento real, o qual é construído pelos diferentes discursos da produção humana, da vida, através da cultura, da linguagem, da ideologia, em que as propostas pedagógicas e curriculares de escolarização são apenas uma parte do seu processo de desenvolvimento curricular. Eis, a nosso ver, os possíveis diálogos e análises entre o cultura, cultura escolar e currículo.

AGRADECIMENTOS: IFC - Campus Camboriú.

\section{REFERÊNCIAS}

ANDRÉ, M. E. D. de. Etnografia da prática escolar. Campinas, SP: Papirus, 1995.

BARDIN, L. Análise de Conteúdo. Lisboa, PT: 70, 2009.

BARROSO, J. (Org.). O Estudo da Escola. Porto: Porto Editora, 1996.

BOURDIEU, P. O poder simbólico. Tradução de Fernando Tomaz. Ed. Bertrand Brasil S.A. Rio de Janeiro. 1989, (159p).

BOURDIEU, P. A reprodução: elementos para uma teoria do sistema de ensino. Textos fundantes de educação. Tradução de Reynaldo Bairão; revisão de Pedro Banjamim Garcia e Ana Maria Baeta. $7^{\text {a }}$ ed. Petrópolis, RJ: Vozes, 2014.

CHAUÍ, M. A ideologia da competência. André Rocha (org). Belo Horizonte: Autêntica Editora; São Paulo: Editora Fundação Perseu Abramo, 2014. 
CHERVEL, A. História das disciplinas escolares: reflexões sobre um campo de pesquisa. Teoria e Educação. Porto Alegre, n. 2, p. 177-229, 1990.

CONTRERAS, J. A autonomia de professores. São Paulo: Cortez, 2002.

FORQUIN, J. Escola e cultura: as bases sociais e epistemológicas do conhecimento escolar. Tradução: Guacira Lopes Louro. Porto Alegre: Artes Médicas, 1993.

GEERTZ, C. A interpretação das culturas. Rio de Janeiro: LTC, 1989.

GHIRALDELLI Jr., P. História da educação. 4. ed. rev. São Paulo: Cortez, 2009.

HALL, S. The centrality of culture: notes on the cultural revolutions of our time. In: THOMPSON, Kenneth (ed.). Media and cultural regulation. London, Thousand Oaks, New Delhi: The Open University; SAGE Publications, 1997. (Cap. 5) Publicado em Educação \& Realidade com a autorização do autor. Tradução e revisão de Ricardo Uebel, Maria Isabel Bujes e Marisa Vorraber Costa.

LARAIA, R. B. Cultura: um conceito antropológico. 13. ed. Rio de Janeiro: Jorge Zahar Editora, 2003.

LIMONTA, S. V. Currículo e formação de professores: um estudo da proposta curricular do curso de pedagogia da universidade estadual de Goiás. 2009. 332 f. Tese (Doutorado em Educação) - Universidade Federal de Goiás. Programa de Pós-Graduação em Educação, 2009.

LOPES, A. C.; MACEDO, E. Teorias de Currículo. São Paulo: Cortez, 2011.

MOREIRA, A. F.; CANDAU, V. M. Educação escolar e cultura(s): construindo caminhos. Rev. Bras. Educ. [online], n. 23, p. 156-168. 2003. ISSN 1413-2478. Disponível em: http://dx.doi.org/10.1590/S1413-24782003000200012. Acesso em: 18 jun. 2017.

MOREIRA, A. F.; CANDAU, V. M. Currículos, disciplinas escolares e culturas. Petrópolis, RJ: Vozes, 2014.

PACHECO, José Augusto. Currículo: Teoria e Práxis. 3 ed. Porto: Porto Editora, 2001.

SACRISTÁN, J. Gimeno. O currículo: uma reflexão sobre a prática. ed. Porto Alegre: Artmed, 2000.

SANTOS, J. L. O que é cultura. São Paulo: Brasiliense, 2003.

SOUZA, E. M. M. Cultura brasileira - figuras da alteridade. São Paulo: Hucitec, 1996.

VIÑAO-FRAGO, A. El espacio y el tiempo escolares como objeto histórico. In: Warde, M. J. (org). Contemporaneidade e Educação. Temas de História da Educação. Rio de Janeiro: Instituto de Estudos da Cultura da Educação, 2000. 
VIÑAO-FRAGO, A. Tiempos Escolares, Tiempos Sociales. Barcelona: Editorial Ariel, 2001.

\section{Como referenciar este artigo}

BRANDT, Andressa Graziele.; SILVA, Filomena Lucia Gossler Rodrigues da.; FERNANDES, Sonia Regina de Souza.; NASCIMENTO, Franc-Lane Sousa Carvalho do.; MAGALHÃES, Nadja Regina Sousa.; MORAIS, Joelson de Sousa. Percepções dos estudantes de licenciatura acerca do conceito de currículo: implicações da cultura e cultura escolar na educação. Revista on line de Política e Gestão Educacional, Araraquara, v. 23, n. 1, p. 175-201, jan./abr., 2019. E-ISSN: 1519-9029. DOI: 10.22633/rpge.v23i1.11970

Submetido em: 09/12/2018

Revisões requeridas: 18/12/2018

Aprovado em: 30/12/2018

Publicado em: 02/01/2019 